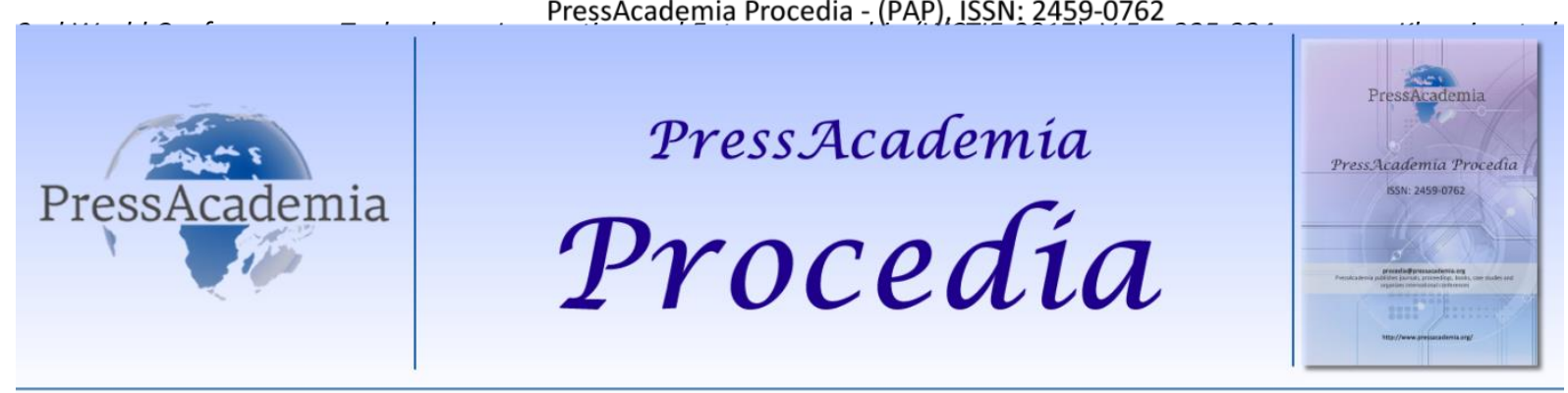

2nd World Conference on Technology, Innovation and Entrepreneurship

May 12-14, 2017, Istanbul, Turkey. Edited by Sefer Şener

\title{
PREDICTING PRESSURE LEVEL FELT UNDER THE SEAT PAN DUE TO CHANGES IN DRIVING POSITION
}

\section{DOI: 10.17261/Pressacademia.2017.607 \\ PAP-WCTIE-V.5-2017(45)-p.325-334}

Khamis, N.K. ${ }^{1}$, Deros, B.M. ${ }^{1}$, Schramm, D. ${ }^{2}$, Maas, N. ${ }^{2}$, Nuawi, M.Z. ${ }^{1}$, and Koppers, ${ }^{2}{ }^{2}$

${ }^{1}$ Universiti Kebangsaan Malaysia, Malaysia, kamaliana@ukm.edu.my

${ }^{2}$ University of Duisburg-Essen, Germany

\begin{abstract}
In ergonomics perspective, car seat is defined as one of the main workstation when the driver is performing driving task. The car seat itself provides support and space for the driver over the head, at the upper and lower back, at the buttock and also at the thigh. There has been abundant research regarding car seat in the past decades. However, in spite of vast studies on this issue, limited studies were found on sitting effect to the pressure when adopting different driving position. Hence, this study integrates objective and subjective evaluation to predict pressure felt level. Mapping of the pressures distribution was taken to the seat pan. This study is a static field experiment where data acquired are in the quantitative form. Findings show that the pressure of the heavier subject is more scattered at the buttock area, while the lighter subject has mild stress concentrated under ischium tuberosity.
\end{abstract}

Keywords: Pressure, car, seat pan, driver, discomfort

\section{INTRODUCTION}

Prolonged sitting and the near static seated posture while driving imposes the driver to be more restricted and has been associated with an increased risk of musculoskeletal disorders (MSDs) such as lower back pain (LBP), neck pain and shoulder pain (Andersson 1980; Balasubramanian \& Prasad 2007). It was caused by the high pressure due to driver's body weight, which leads to an elevated force on the muscles that are functioning in an anaerobic setting. Due to this compressive force at the driver and seat interface, the blood flow will be obstructed through the large vessels to the lower body part. Consequently, it leads to oxygen deficiency, which can be expressed as discomfort and fatigue. In the long run, it will turn to pain and injury (Yamazaki 1992; Graf, Guggenbiihl, \& Krueger 1993; Graf et al. 1995; Wilke et al. 1999; Lueder 2004; Ng, Cassar, \& Gross 1995; Gross et al. 1994)

Many studies in the literature focused on seat improvement. For instance, Grandjean (1980), Hubbard \& Reynolds (1984), Coelho \& Dahlman (1999) and Wu, Rakheja\& Boileau (1999) focused on seat design parameters and features by considering postural angle, design, and materials of the seat. In addition, several studies had combined subjective assessment tools such as comfort rating with the pressure distribution data. Past studies showed that there is a good correlation between pressure distribution data and seat comfort rating. Ng et al. (1995) had conducted another study with the same approach by developing an intelligent seat system based on the pressure data adjustment on the seat. Subjective comfort ratings (from 1=very poor to 10 =very good) and anthropometric measurements were also carried out in this study when 20 respondents were required to simulate driving position in a seating buck. Thakurta et al. (1995) have compared subjective assessment of short and long driving on the 80-mile highway. Thirty-six respondents have evaluated five small cars by using comfort assessment questionnaires and the pressure distribution was mapped before and after driving. Overall, up to this date, limited studies examine the pressure distribution pattern when sitting in a different driving position with the complete set of car setup, and its effect on the driver. There were three studies which are closely associated with this matter. Andreoni et al. (2002) have recorded the posture and pressure distribution when the subject put his foot on the car pedal. However, this study did not have fixed position. In addition, this study did not require the test subjects to drive the 
car. Therefore, there was no result on the pre and post activity. Porter, Gyi \& Tait (2003) conducted a study by asking the subject to drive the car. However, there was no specific posture for this study. Na et al. (2005) had carried out the study by setting the seat back angle at $115^{\circ}$ based on Korean population. However, there was no comparison between different posture.

This paper aims to combine this matter by examining the impact of adopting different fixed driving position based on Malaysian population towards driver when sitting on the actual car's seat pan. Subjective and objective measures assessments were used in this study. Basically, this paper contributes to the literature on the impact of pressure distribution in three ways. First, this paper document an important relationship between characteristics of the sitter, such as weight with pressure distribution. Second, our results support the hypothesis, that there is a good correlation between objective and subjective measure by developing the linear model. Third, our results depict the association between pressure interface pattern as well as different driving positions and its impact on the driver when sitting on the car seat. The paper is organized as follows. Section 2 exhibits methodology of this research work. Section 3 reports and explains the empirical findings and analysis of this research. And the final section provides conclusions for this study.

\section{RESEARCH METHODOLOGY}

\subsection{Test Subjects}

Twelve female subjects (mean age of 29 years, mean height $=156 \mathrm{~cm}$, mean weight $=54 \mathrm{~kg}$ ) were assigned from the population of staff and students at Universiti Kebangsaan Malaysia (UKM) to take part in this simulator study. Gender criteria was focused on female only to reduce variations in the findings, due to male and female have major different in body charateristics and driving behavior. Each subject was required to attend one session, either in the morning session (from $9 \mathrm{am}$ to $12 \mathrm{pm}$ ) or in the evening session (from $2 \mathrm{pm}$ to $5 \mathrm{pm}$ ). The inclusion criteria were all respondents held a full Malaysia driving license, had at least 3 years of driving experiences and aged between 22 to 35 years. The constriction of the age range was proposed to reduce variations in the results due to age since even in normal aging, people present slight perceptive variations that have a direct attitude towards driving (Antonson et al. 2014). However, for this study there were three cases of data conflict and error during data collection. Therefore, only data from nine subjects had been used for further analysis.

All subjects were allowed to adapt with the car simulator setup and car seat adjustment before starting the experiment. The experiment was started after five minutes the subject had been in the driving position to allow them to adapt with the seat environment and fabrics. All subjects understood and complied with the oral and written instructions provided by researcher for this experiment. Information about the experiment procedure and questionnaires used was included. After receiving the complete information on the study, each subject signed an informed consent. However, before starting the experiment, the subjects were required to test the simulator in order to ensure they were familiar with the car's component; gears, steering, and acceleration as well as the simulator road condition and landscape. All subjects were instructed to drive and obey road rules for 15 minutes for each driving positions. Figure 1 demonstrates the process flow of the instruction for the subject. Section 2.2 describes the design of the simulator setup.

All subjects were allowed to adapt with the car simulator setup and car seat adjustment before starting the experiment. The experiment was started after five minutes the subject had been in the driving position to allow them to adapt with the seat environment and fabrics. All subjects understood and complied with the oral and written instructions provided by researcher for this experiment. Information about the experiment procedure and questionnaires used was included. After receiving the complete information on the study, each subject signed an informed consent. However, before starting the experiment, the subjects were required to test the simulator in order to ensure they were familiar with the car's component; gears, steering, and acceleration as well as the simulator road condition and landscape. All subjects were instructed to drive and obey road rules for 15 minutes for each driving positions. Figure 1 demonstrates the process flow of the instruction for the subject. Section 2.2 describes the design of the simulator setup. 
Figure 1: Experiment Flow for Each Subject

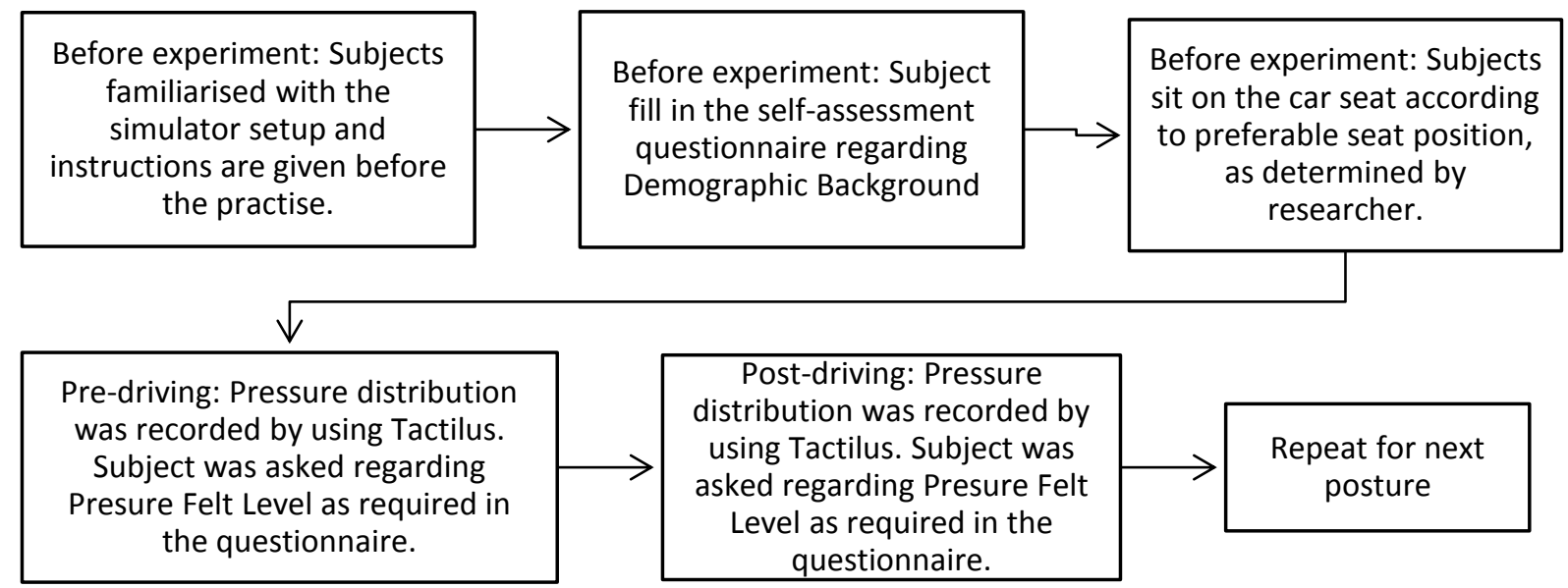

\subsection{Simulator Setup}

A simulator was used in this study as displayed in Figure 2. This simulator was located in the Ergonomics Laboratory, Department of Mechanical and Materials Engineering, Faculty of Engineering and Built Environment, UKM. This simulator design and car seat parameters were quite similar to one of the national compact cars in Malaysia. The simulator consists of an adjustable driver's seat (inclination of the backrest, lower or elevate head rest, forward or backward seat), steering wheel, clutch, accelerator and brake pedals, handbrake, and manual gear shift. The screen was arranged in front of the driver and has the virtual dashboard on it when using the simulator.

\section{Figure 2: Simulator Setup}

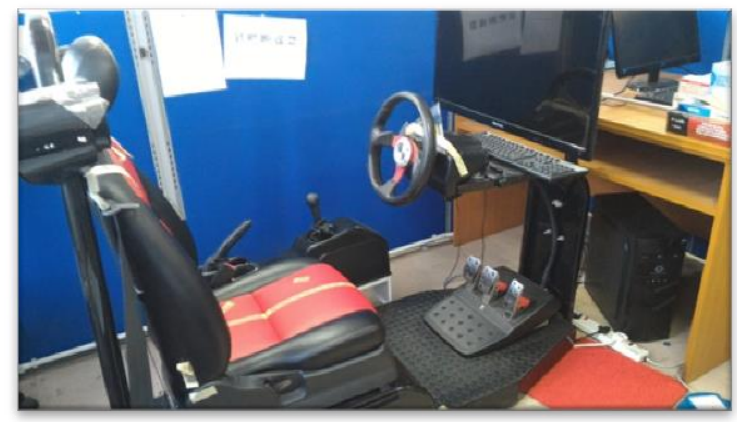

The driving task was reduced to a lane keeping task to induce task monotony: no traffic, driving consisted in following a lane (no itinerary involved) with speed in between 50 to 70 kilometres per hour, without having to stop the car (no red traffic lights, stops) or having the need for frequent breaking intervals (no T junctions inter-sections or perpendicular turns), or having the necessities for gear and lane changings during the driving task (only change gear to gear 5 at the beginning), as well as turn signals activation. In addition, driving at the suburban scene was selected for this experiment. The simulated driving task was designed with the following requirements: the route was simple so that the drivers could complete the task easily, there were few scenery changes, there was no inclination on driving route to reduce outside stimuli, and light curvature was chosen so that drivers had to pay attention. However, there are different road characteristics along the driving journey. Some road surfaces is quite bumpy and the driver can see this change in the scene when driving.

\subsection{Experiment Design and Procedure}

Two different driving positions with fixed backrest position at $100^{\circ}$ were carried out in this study, as depicted in Figure 3(a) and (b). This fixed position at the back rest was based on the past study conducted by Daruis (2010), Mohamad et al. (2010) and Mohamad et al. (2016). Two different driving position were: i) Posture A: closest distant to car controls and ii) Posture B: far distant from car controls, as long as the test subjects could operate the car controls and sat comfortably leaning against backrest of the car seat. During recording the pressure distribution, the test subject have to place their hand at 10 
and $2 o^{\prime}$ clock as shown in Figure 3. In addition, the subject needed to ensure the right leg at the car pedal, while the left leg at the car simulator floor, near to clutch pedal.

\section{Figure 3: Driving posture}

\section{(a) Posture A}

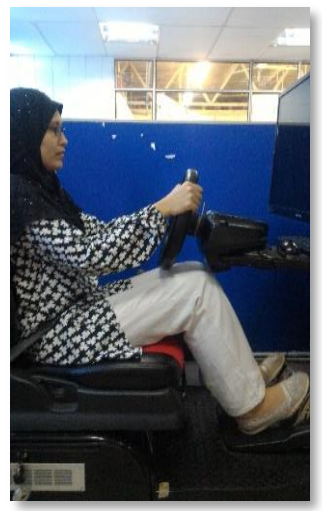

(b) Posture B

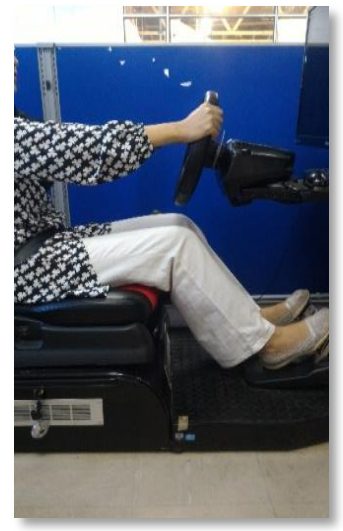

As mentioned in Section 2.1, each subject was required to drive the simulator for 15 minutes. As mentioned by Porter, Gyi \& Tait (2003), some seats are considered uncomfortable after approximately 15 minutes. In addition, Shackel et al. (1969), also took 15 minutes as the ultimate time to evaluate the sitting comfort on ten chairs. Therefore, 15 minutes of driving task for each driving position should be enough to investigate the driver's state pattern. This pattern can be seen from pressure distribution measurement and pressure felt assessment on pre (before) and post (after) driving activity. Section 2.4 and 2.5 explained on the pressure distribution measurement and self-assessment questionnaire design.

\subsection{Pressure Distribution Measurement}

Pressure measure is sensitive to postural changes of varied angulation and has good correlation with subjective comforts, by determining the maximum pressure, average pressure ratio and maximum pressure gradient (de Looze, Kuijt-Evers, \& van Dieën, 2003; Shen \& Galer, 2015). In this study, the Tactilus ${ }^{\circledR}$ pressure mapping from Sensor Products Incorporations (SPI) was used as shown in Figure 4. The system includes a $22 \times 22$ sensor pad calibrated 0-5psi with $32 \times 32$ sensor matrix. The interface pressure uses thin and flexible sensor arrays. By scanning the grid and measuring the electrical resistance at each grid point, the pressure distribution on the sensor's surface can be determined. The scanning electronics are packaged in a handle assembly that clips onto the sensor's interface tab and provides the electrical connection to each sensing cell. 
Figure 4: Tactilus $^{\circledR}$ Pressure Mat

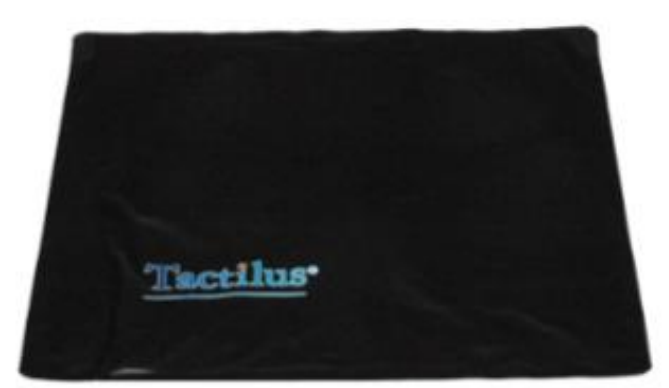

All subjects were requested to wear suitable clothes for driving but without heavy seams, buttons or pockets in order that there was minimal effect on the pressure readings. This requirement is necessary to avoid false seat or backrest interface pressure readings. These mats were securely attached to the seat using strips of masking tape. Care was exercised to ensure that the mats were placed in a consistent location from subject and seat or backrest. Subjects adopted the driving positions for this measurement (hands on the steering wheel and looking ahead), held for 30 seconds. Then, the pressure distribution measurement of pre and post driving for the car seat was taken about one minute for each position. The mats were removed and the occupant was asked to re-enter the seat in order to complete the survey without interference from the mats. The reason behind this instruction was, subjects faced difficulty in rating the appearance of the seat if they were sitting on it.

\subsection{Design of Self-Assessment Questionnaire}

The first section required the subject to provide the information regarding age, gender, height, weight and driving experience. Next section required the test subject to identify the perception of pressure felt level based on driving posture. In this section, seat part assessment was categorized into two segments, buttock and thigh. This section used the Visual Analogue Scale (VAS) for perception of pressure felt. Basically, VAS is referred to $10 \mathrm{~cm}$ continuous horizontal line with each point have a different definition. In this case, 0 was referred as no pressure felt, and 10 referred to the extreme pressure felt.

\subsection{Statistical Analysis}

Data from the experiment was used to predict and estimate the dependent variable (DV) based on independence variable (IV) by using the Regression Method. It was used to predict the value of a variable based on the value of another variable. The variable to predict is called the DV, while the variable to predict the other variable's value is called the IV or known as the predictor variable. In this study, the DV is based on the subjective assessment, while the IV is referred to the objective assessment (pressure distribution map measurement). The highest mean score for each IV had been used to develop the model in this section. Only data from pre-driving activity was used because it provides more accuracy, where the subject have enough break time in between driving position before conducting the experiment for each task.

Based on this method, the regression coefficient (K), regression constant (c), multiple correlation coefficients (R), coefficients of determination $\left(R^{2}\right)$ and significance level $(p)$ can be determined. The acceptance or rejection of the null hypothesis $(\mathrm{Ho})$ for this study can also be determined based on the newly developed model $\left(H_{0}: \beta 1=0\right.$ and $\beta 2=0: \beta 1 \neq 0$ and $\beta 2 \neq 0$ ). The $H_{0}$ can be rejected if the $p$-value is low $(p<0.05)$. As a result, it can estimate the drivers' condition based on these integrated assessment methods. In other words, a predictor that has a low $p$-value is likely to be a significant predictor to the model because changes in the predictor's value are connected to changes in the response variable. The linear equation to predict the drivers' state was demonstrated in Equation (1).

$$
\mathrm{Y}=\mathrm{K}_{1} \mathrm{X}_{1}+\mathrm{c}
$$

Where;

$\mathrm{Y}=$ Drivers' state based on subjective assessment (DV)

$K=$ Regression coefficient as the contributor factor towards pressure pattern

$\mathrm{X}=$ Factor that contributes towards pressure pattern (IV)

$c=$ Regression constant 


\section{FINDINGS AND DISCUSSIONS}

This section describes the findings for the pre-driving task and posts driving task from the seat pan. This section explains the seat pan pressure distribution's findings by focusing on the Body Mass Index (BMI) and percentile group of all subjects.

\subsection{Seat Pan Interface Pressure Between Subjects According to the BMI and Percentile}

Figure 5(a), (b) and (c) illustrate three examples of the pressure distribution for the seat pan from three representatives of the underweight subject $(B M I=17.1)$, normal weight subject $(B M I=20.8)$ and overweight subject $(B M I=27.3)$ from the Tactilus software and conversion Excel $32 \times 32$. With regards to the Figure 5 (a) to (c), the pressure of the heavier subject is more scattered at the buttock area, while the lighter subject has mild stress concentrated under ischium tuberosity.

Figure 5: Pressure distribution pattern based on the BMI for the seat pan

(a) Underweight subject (UW)

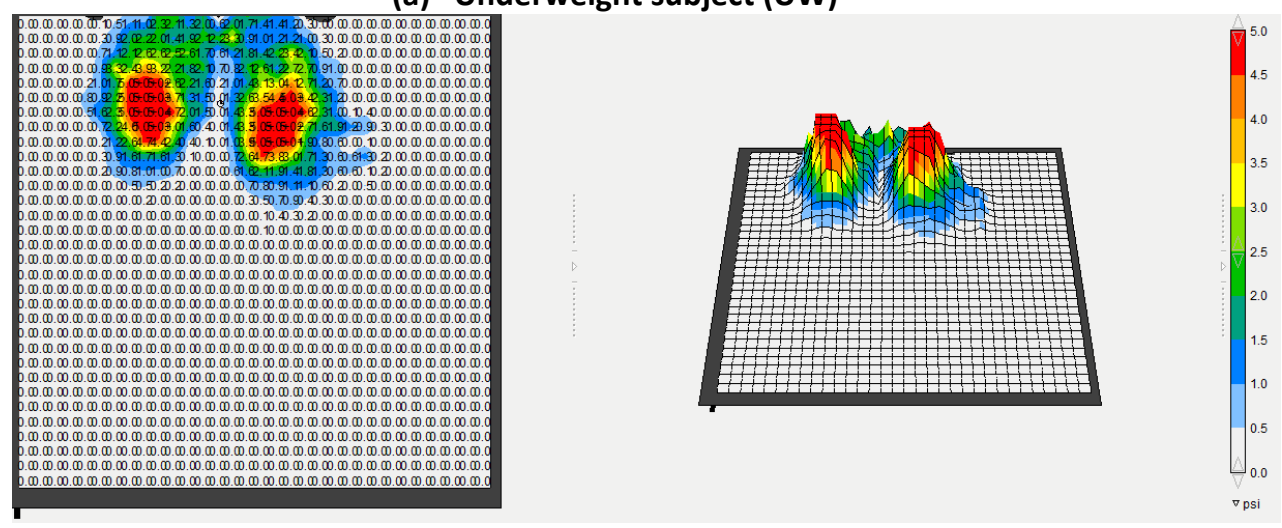

(b) Normal weight subject (NW)

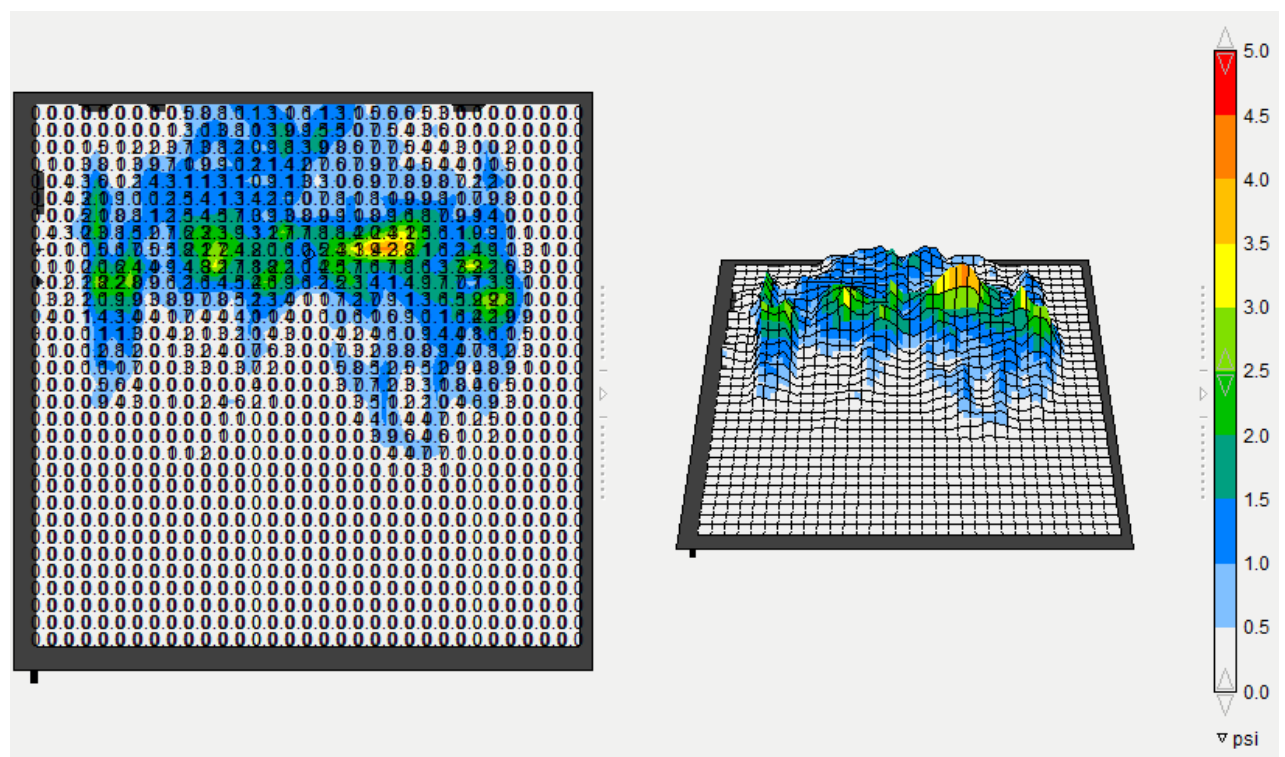




\section{(c) Overweight subject (OW)}

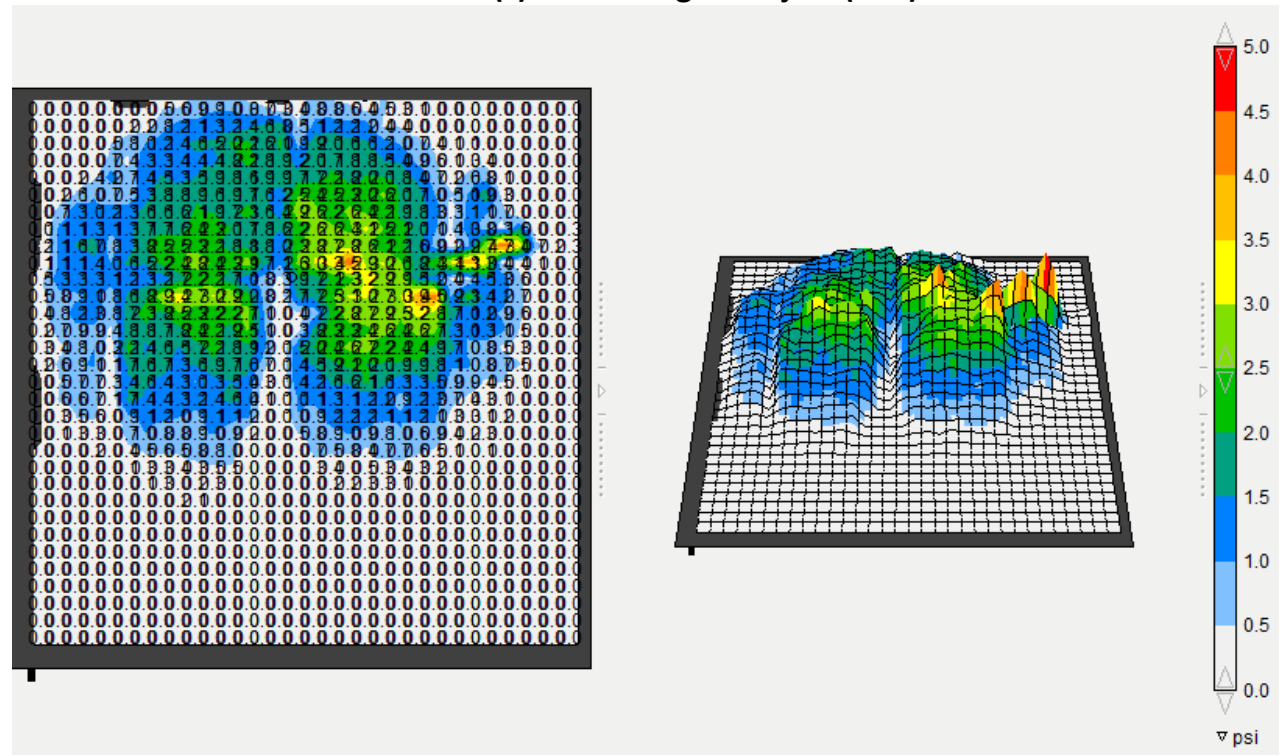

Table 1 demonstrates the mean pressure of each driving position for all subjects according to the percentile group. The percentile value used in this study is primarily referred to past study conducted by Daruis (2010) based on Malaysian population. Mean percentile or denoted as the 50th percentile for this case is $1.567 \mathrm{~cm}$ (height) and $54 \mathrm{~kg}$ (weight). Based on Table 1 without considering the percentile group, the buttock part is significantly higher than the thigh part, with the mean pressure is in between 1 to 2 psi. Moreover, generally, the group with below 50th percentile produces the highest mean pressure for the buttock part. It is because the highest mean pressure was concentrated under ischium tuberosity. As a result, the pressure value at the buttock part of this group was significantly higher. Meanwhile, the group with above 50th percentile generates the highest mean pressure at the thigh due to a scattered pattern of the pressure distribution. Next subsection clarifies the actual pattern based on these findings with the aid of the graph illustration and statistical analysis.

Table 1: Seat Pan Pressure Distribution According to the Body Size for Posture A and B

\begin{tabular}{lcccc}
\hline & \multicolumn{3}{c}{ Percentile $<$ 50th } & \multicolumn{2}{c}{ Percentile $>$ 50th } \\
\cline { 2 - 5 } Percentile & Mean & SD & Mean & SD \\
\hline A pre-buttock & 2.71 & 0.74 & 2.64 & 0.31 \\
B pre-buttock & 2.20 & 0.41 & 1.96 & 0.11 \\
A post buttock & 3.59 & 1.06 & 2.79 & 0.73 \\
B post buttock & 3.20 & 0.80 & 2.47 & 0.50 \\
A pre-thigh & 0.56 & 0.54 & 1.05 & 0.25 \\
B pre-thigh & 0.94 & 0.43 & 1.14 & 0.40 \\
A post thigh & 0.74 & 0.52 & 0.98 & 0.45 \\
B post thigh & 1.40 & 0.51 & 1.40 & 0.51 \\
\hline
\end{tabular}

\subsection{Relationship Between Pressure Distribution Map And Pressure Felt Level}

As described in Section 2.6, from the subjective and objective assessment for pre-driving activity, the highest pressure value was indicated at the buttock part at posture $A$ with the mean pressure score were 6.24 and 2.67 psi from both assessments respectively. Therefore, for this part, the DV was the data from the subjective assessment (posture A-buttock pre-activity), meanwhile, the IV was the data from the pressure distribution measurement at the buttock part at posture A (pre-activity). Before performing the Regression Analysis, the unit of the pressure distribution had been converted to SI unit (from psi to $\mathrm{kg} / \mathrm{cm}-2$ ). This action was applied to ensure the standardization of the unit for all variables in the model. 
Table 2 shows the findings from the Regression Method. This table provides the $R, R^{2}$, Adjusted $R^{2}$, and the Standard Error of the Estimate (SEE), which can be used to determine how well a regression model fits the data. $R$ can be considered to be one measure of the quality of the prediction of the DV; in this case, the pressure felt by the subject. A value of 0.963 indicates a good level of prediction. In general, if $\mathrm{R}$ value is more than 0.71 , it shows that there was a strong correlation between variable (Piaw 2006). The $R$ Square column represents the $R^{2}$ value, which is the proportion of variance in the dependent variable that can be explained by the IV. Based on Table 5.1, 92.7\% explained the variability of the DV. The Adjusted R Square is intended to control for overestimates of the population R square resulting from small samples. In this case, the Adjusted R Square was 0.916, smaller than R Square. Meanwhile, the SEE is the standard deviation of the residuals. As the $\mathrm{R}$ Square increases, the SEE will decrease. In this case, the SEE is 0.281.

Table 2: Summary of the Model for Pressure Distribution and Pressure Felt Level

\begin{tabular}{ccccc}
\hline Model & R & R Square & Adjusted R Square & SEE \\
\hline 1 & 0.963 & 0.927 & 0.916 & 0.281 \\
\hline
\end{tabular}

Table 3 shows the ANOVA table for the pressure model at the buttock. The F-ratio in Table 5.2 indicates whether the overall regression model is a good fit for the data. The table shows that the IV statistically significantly predict the DV, $F(1,7)=$ $88.254, \mathrm{p}<.0005$.

Table 3: ANOVA Table of the Pressure Distribution and Pressure Felt Perception

\begin{tabular}{ccccccc}
\hline & Model & & Sum of & df & Mean Square & F \\
& Squares & & & Sig. \\
\hline \multirow{2}{*}{1} & Regression & 6.951 & 1 & 6.951 & 88.254 \\
& Residual & 0.551 & 7 & 0.079 & \\
& Total & 7.502 & 8 & & \\
\hline
\end{tabular}

Table 4 depicts the coefficient table for this model. This table provides the general form of the equation to predict the pressure felt by the subject. Unstandardized coefficients indicate how much the DV varies with an IV when all other IV (if any) are held constant. According to Table 5.3, the significant level for constant and the IV (pressure distribution at the buttock) were less than 0.05 . It indicates the possibility to obtain $t$ value for the constant was 2.393 , the slope for pressure distribution at the buttock was 9.394. Therefore, the $\mathrm{HO}$ would be rejected ( $\mathrm{HO}: \beta 1=0$ and $\beta 2=0$ ).

Table 4: Coefficient Table for the Pressure Distribution and Pressure Felt Perception

\begin{tabular}{|c|c|c|c|c|c|c|}
\hline \multirow{2}{*}{\multicolumn{2}{|c|}{ Model }} & \multicolumn{2}{|c|}{$\begin{array}{c}\text { Unstandardized } \\
\text { Coefficient }\end{array}$} & \multirow{2}{*}{$\begin{array}{c}\begin{array}{c}\text { Standardized } \\
\text { Coefficient }\end{array} \\
\text { Beta }\end{array}$} & \multirow[t]{2}{*}{$\mathbf{t}$} & \multirow[t]{2}{*}{ Sig. } \\
\hline & & $\mathrm{B}$ & Std. Error & & & \\
\hline \multirow[t]{2}{*}{1} & Constant & 1.284 & 0.536 & & 2.393 & 0.048 \\
\hline & $\begin{array}{c}\text { Pressure distribution } \\
\text { map at the buttock }\end{array}$ & 1.860 & 0.198 & 0.963 & 9.394 & 0.000 \\
\hline
\end{tabular}

With regards to Table 4, the equation model to predict the drivers' state based on pressure felt at the buttock can be used. It was indicated in Equation (2):

$$
\mathrm{Y}=1.86 \mathrm{X}_{1}+1.284(2)
$$

Based on the findings, there was a strong evidence that the pressure distribution data at the buttock was a significant predictor to estimate the perception on pressure felt at the buttock. It was shown by the standardized coefficient magnitude, Beta $(\beta)=0.963$. In addition, as mentioned earlier, pressure distribution data at the buttock explained $92.7 \%$ from the variance occurred. It was explained at the significance level, $\alpha=0.05(5 \%)$ or at confidence level $95 \%$.

\section{CONCLUSION}

All in all, this study shows that the distribution of pressure over seat pan was slightly influenced by the characteristics of the sitter's body part, in term of the weight and also buttock-knee length as mentioned in the thorough analysis of the seat pan. Based on the findings from the seat pan, the pressure of the heavier subject is more scattered at the buttock area, while the lighter subject has mild stress concentrated under ischium tuberosity. With regards to driving position, posture $\mathrm{A}$ depicted the highest mean pressure at the buttock compared to posture B. In term of driving position, there is a difference in all postures at the buttock. Based on the model, a linear regression was run to predict the pressure felt from pressure distribution map. This variable statistical significantly predicted the pressure felt, $F(1,7)=88.254, p<0.0005, R 2=0.927$. In 
addition, due to the low value of $p(p<0.05)$, the Ho $(\mathrm{Ho}: \beta 1=0)$ was rejected. Hence, the linear model to predict the pressure felt at the buttock was: $\mathrm{Y}=1.86 \mathrm{X}_{1}+1.284$.

\section{REFERENCES}

Andersson, G.B.J. 1980. The load on the lumbar spine in sitting postures. D.J. Oborne and J.A. Levis (eds.) Human Factors in Transport Research. New York: Academic Press, 231-239.

Andreoni, G., Santambrogio, G.C., Rabuffetti, M., \& Pedotti, A. 2002. Method for the analysis of posture and interface pressure of car drivers. Applied Ergonomics, 33(6): 511-522.

Antonson, H., Ahlström, C., Mårdh, S., Blomqvist, G., \& Wiklund, M. 2014. Landscape heritage objects' effect on driving: a combined driving simulator and questionnaire study. Accident Analysis and Prevention, 62: 168-177.

Balasubramanian, V., \& Adalarasu, K. 2007. EMG-based analysis of change in muscle activity during simulated driving. Journal of Bodywork and Movement Therapies, 11(2): 151-158.

Coelho, D.A., \& Dahlman, S. 1999. A pilot evaluation of car seat side support : Leading to a redefinition of the problem. International Journal of Industrial Ergonomics, 24: 201-210.

Daruis, D.D.I. 2010. Model bersepadu untuk pengukuran dan penilaian tahap ketidakselesaan tempat duduk kereta. Tesis Doktor Falsafah, Universiti Kebangsaan Malaysia.

De Looze, M.P., Kuijt-Evers, L.F.M., \& van Dieën, J. 2003. Sitting comfort and discomfort and the relationships with objective measures. Ergonomics, 46(10): 985-997.

Graf, M., Guggenbiihl, U., \& Krueger, H. 1993. Investigations on the effects of seat shape and slope on posture, comfort and back muscle activity. International Journal of Industrial Ergonomics, 12: 91-103.

Graf, M., Guggenbuhl, U., \& Krueger, H. An assessment of seated activity and postures at five workplaces. International Journal of Industrial Ergonomics, 15(2): 81-90.

Grandjean, E., 1980. Sitting posture of car drivers forms the point of view of ergonomics. Hum. Fact. Trans. Res., 2: $205-213$.

Gross, C.M., Goonetilleke, R.S. and Menon, K.K., 1994. New developments in the biomechanical assessment and prediction of seat comfort. Hard facts about soft machines: The ergonomics of seating.

Hubbard, R.P., \& Reynolds, H. M. 1984. Anatomical geometry and seating. SAE Technical Paper 840506. Warrendale, PA: Society of Automotive Engineers, Inc

Lueder, R. 2004. Ergonomics of seated movement: A review of the scientific literature. Humanics Ergosystem Inc.

Mohamad, D., Deros, B.M., Daruis, D.D.I., Ramli, N.F., \& Sukadarin, E.H. 2016. Comfortable driver's car seat dimensions based on anthropometrics data. Iranian Journal of Public Health, 45(1): 106-113.

Mohamad, D., Deros, B.M., Wahab, D.A., Daruis, D.D.I., \& Ismail, A.R. 2010. Integration of comfort into a driver's car seat design using image analysis. American Journal of Applied Sciences, 7(7): 937-942

Na, S., Lim, S., Choi, H.-S., \& Chung, M.K. 2005. Evaluation of driver's discomfort and postural change using dynamic body pressure distribution. International Journal of Industrial Ergonomics, 35(12): 1085-1096.

Ng, D., Cassar, T., \& Gross, C.M. 1995. Evaluation of an intelligent seat system. Applied Ergonomics, 26(2): 109-116.

Piaw, C.Y. 2006. Asas statistik penyelidikan. Cetakan Pertama. Shah Alam, Selangor: McGrraw-Hill (Malaysia).

Porter, J.M., Gyi, D.E. \& Tait, H.A., 2003. Interface pressure data and the prediction of driver discomfort in road trials. Applied Ergonomics, 34(3): 207-214.

Porter, J.M., Gyi, D.E. \& Tait, H.A., 2003. Interface pressure data and the prediction of driver discomfort in road trials. Applied Ergonomics, 34(3): 207-214

Shackel, B., Chidsey, K.D., Shipley, P., 1969. The assessment of chair comfort, Ergonomics, 12(2): 269-306

Shen, W., \& Galer, I.A.R. 2015. Development of a pressure related assessment model of seating discomfort. Proceedings of the Human Factors and Ergonomics Society Annual Meeting.

Thakurta, K., Koester, D., Bush, N., Bachle, S. 1995. Evaluating short and long term seating comfort. Society of Automotive Engineers, 950144. 
Wilke, H.J., Neef, P., Caimi, M., Hoogland, T. \& Claes, L.E. 1999. New in vivo measurements of pressures in the intervertebral disc in daily life. Spine, 24(8): 755-762

Wu, X., Rakheja, S., \& Boileau, P.-É. 1999. Distribution of human-seat interface pressure on a soft automotive seat under vertical vibration. International Journal of Industrial Ergonomics, 24(5): 545-557.

Yamazaki, N. 1992. Analysis of sitting comfortability of driver's seat by contact shape. Ergonomics. 35(5-6): 677-692. 